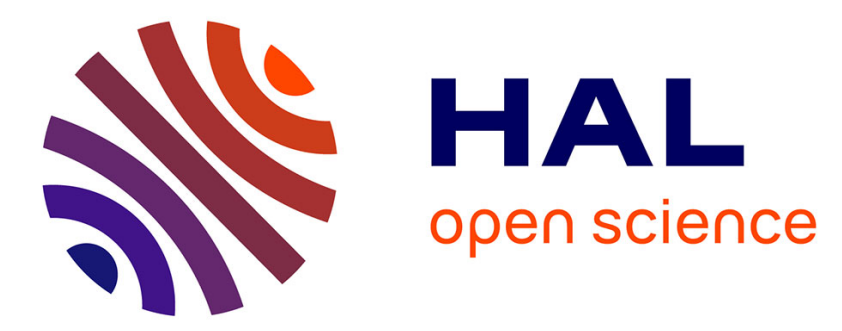

\title{
Melatonin in children with autistic spectrum disorders: recent and practical data
}

C. Doyen, D. Mighiu, K. Kaye, C. Colineaux, C. Beaumanoir, Y. Mouraeff, C. Rieu, P. Paubel, Y. Contejean

\section{- To cite this version:}

C. Doyen, D. Mighiu, K. Kaye, C. Colineaux, C. Beaumanoir, et al.. Melatonin in children with autistic spectrum disorders: recent and practical data. European Child and Adolescent Psychiatry, 2011, 20 (5), pp.231-239. 10.1007/s00787-011-0162-8 . hal-00674185

\section{HAL Id: hal-00674185 \\ https://hal.science/hal-00674185}

Submitted on 26 Feb 2012

HAL is a multi-disciplinary open access archive for the deposit and dissemination of scientific research documents, whether they are published or not. The documents may come from teaching and research institutions in France or abroad, or from public or private research centers.
L'archive ouverte pluridisciplinaire HAL, est destinée au dépôt et à la diffusion de documents scientifiques de niveau recherche, publiés ou non, émanant des établissements d'enseignement et de recherche français ou étrangers, des laboratoires publics ou privés. 


\section{TITLE PAGE}

\section{Authors}

- Doyen C. (1)

- Mighiu D. (1)

- Kaye K. (1)

- Colineaux C. (1)

- Beaumanoir C. (2)

- Mouraeff Y. (2)

- Rieu C. (2)

- Paubel P. (2)

- Contejean Y. (2)

\section{Title}

Melatonin in children with autistic spectrum disorders: recent and practical data

\section{Address}

(1) Department of Child and Adolescent Psychopathology, Sainte Anne Hospital, 14 rue Cabanis, 75014 Paris, France

(2) Department of Pharmacy and Sterilization, Sainte Anne Hospital, 14 rue Cabanis, 75014 Paris, France

\section{E-mail: c.doyen@ch-sainte-anne.fr}

Tel : (+33) -1- 45- 65- $87-74$

Fax : (+33) -1 -45 -65 -83- 06 


\begin{abstract}
Over the last twenty years, melatonin, a pineal hormone synthesised from serotonin, has been implicated in various studies on the autism spectrum disorder (ASD) and altered melatonin levels were detected in subgroups of subjects with ASD. Its effect on sleep disturbances got the attention of clinicians and several investigations were carried out in order to determine the usefulness and safety of melatonin administration in this disorder. Hypotheses were also raised regarding the possibility that the dysfunctional synthesis and secretion of melatonin detected in subgroups of subjects with ASD may increase the risk as well the severity of ASD. The purpose of this paper is to review our pharmacokinetic knowledge on melatonin and present results from recent studies on sleep disorders in autism, their treatment with melatonin and the impact of melatonin prescription in children with ASD evaluated in a Diagnostic Center for Autism Spectrum Disorder in Paris, France.
\end{abstract}

\title{
KEY WORDS
}

Melatonin, Autism, Childhood, Sleep, Disorders 


\section{MELATONIN IN CHILDREN WITH AUTISTIC SPECTRUM DISORDERS: RECENT AND PRACTICAL DATA}

Autism affects at least 6/1000 individuals and describes a spectrum of neurobehavioral developmental disorders characterized by deficits in social interaction and communication, with repetitive behaviour and a limited repertoire of interests, but also impairments in cognition, language, body movements and adaptive abilities.

Despite the fact that sleep is one of the major concerns for families having a child with autism, the abnormalities of sleep were often considered as an epiphenomenon and therefore did not catch the attention of the scientific community until the last few years. Nevertheless, clinicians are confronted with sleep disorders in children with autism and the nervous exhaustion of their families. Usual treatments with anxiolytics or neuroleptics are not satisfying enough and new therapeutics are needed. In France, melatonin is authorized by regulatory health authorities but it is not indicated for use in children. However, melatonin is often successfully used by clinicians and despite a lack of data concerning the effects of this treatment $[9,24]$ This paper presents current literature about melatonin and its links with autism. Its practical use and effects in children evaluated in a French Diagnosis Center for Autism Spectrum Disorders are also described.

\section{MELATONIN: PHARMACOKINETICS}

Melatonin is found diffusely in nature, in plants, lower phyla and animals and is the predominant and the best known human pineal hormone. The first described biological activity of it was made by McCord and Allen in 1917 and it was isolated in 1958 by A. Lerner and coll. who elucidated its chemical structure [7].

Synthesis Pineal-derived melatonin is an indole amine, synthesized from tryptophan, through serotonin, with the rate-limiting step catalyzed by the enzyme arylalkylamine $\mathrm{N}$-acetyl transferase (AANAT). Hydroxyindol-Omethyltransferase (HIOMT) catalyzes the final step of melatonin synthesis and may play the same role of the rate-limiting step in the melatonin synthesis. Once synthesized in the pineal gland melatonin is released into the capillaries and distributed to the body tissues. Then it binds to specific seven-membrane, G-protein-coupled receptors at various sites, of which the suprachiasmatic nucleus of the hypothalamus (SCN) is the best characterized [15].

The half-life of melatonin exhibits a biphasic pattern, with a first distribution of 2 minutes and a second of 20 minutes. The circulating hormone is catabolized by hepatic and kidney ways [33]. 
Receptors Melatonin has multiple receptors-mediated and receptors -independent actions and mediates its effects by acting on a family of $\mathrm{G}$ protein-coupled receptors, which have been characterized by pharmacologic, neuroanatomic and molecular approaches. The first member of the family, the MT1 receptor, was found in the $\mathrm{SCN}$, the retina, and the pars tuberalis of the adenohypophysis. The MT2 receptor is also expressed in the retina and the brain, particularly the SCN, but at much lower levels of density. Many of the effects of the melatonin on the circadian rhythms involve actions of the MT1 receptors, which may play a role in altering the SCN state of excitability as the clock shifts from day to night, by inhibiting neuronal activity in the SCN and/or other areas of the limbic system. By contrast, activation of the MT2 receptor coincides with the time of rise and fall of melatonin production. MT3 receptor may be involved in cellular detoxification and might account for some of melatonin's effects as an antioxidant. The expression of the MT1 receptors in the human SCN decreases with advancing age as well as in the late stages of Alzheimer's disease [33,35].

Levels Synthesis and release of melatonin in the pineal gland and retina follow a circadian rhythm. In healthy humans, in a "normal environment", melatonin is secreted during the night. The average maximum levels attained in plasma in adults are about 60 to $70 \mathrm{pg} / \mathrm{ml}$ and minimum concentration is usually below 10pg/ml [7] Peak concentrations in plasma occur between 2 and 4 a.m. with an onset of secretion usually around 9 to 10 p.m. and an offset usually at 7 to 9 a.m. in adults in temperate zones. Levels in saliva are in generally about $1 / 3$ of those in plasma [15]. Large interindividual variations were described and a small number of apparently normal individuals have no detectable melatonin in plasma at any time of day [7].

During foetal life circadian changes are regulated by maternal circadian rhythms and this maternal regulation may be mediated by circulating melatonin [15]. Shortly after birth, little melatonin is detectable in body fluids. A robust melatonin rhythm appears around 6 to 8 weeks of life and increases rapidly thereafter. At the age of 1-3 years old a peak value is observed, and melatonin reaches a lifetime peak when children are on average 3- 5 years of age. A decline occurs shortly before puberty related to increased body mass. Values remains relatively unchanged from 35 to 40 years of age, and a final decline of amplitude then takes place until low levels are seen in old age, with the exception of one study using very healthy elderly subjects $[7,15]$. The exogenous melatonin, has a limited bioavailability, as well as a highly variable pharmacokinetic profile, with interindividual differences, which explain partially the differential responses seen in individuals who take melatonin orally [33]. Control Melatonin synthesis depends upon exogenous or endogenous factors (light, seasons, sex,age,pubertal status) [38]. For example, even brief exposure to light suppresses melatonin production at night. The retina, the suprachiasmatic nucleus ( $\mathrm{SCN}$ ) of the hypothalamus and the pineal gland together form the basic structures that 
perceive and transduce the non-visual effects of light [7]. This basic structure integrates information encoded by light into coordinated secretions that underlie biologic rhythmicity [15]. Melatonin forms a close loop between the tissues, the SCN and the pineal gland. It plays a key role in regulating a myriad of circadian rhythms and its synthesis is exquisitely controlled. This control is exerted at several levels, including also the AANAT mRNA levels and AANAT activity. Norephinephrine is the neurotransmitter released from the synapses of postganglionic sympathetic neurons and which acts on B-adrenergic receptors in pinealocytes. The light or the lack of it, acting through the sympathetic nervous system, induces an increase in cAMP, representing a fundamental regulator of AANAT transcription and melatonin synthesis. In the same time the control of AANAT is more often posttranscriptional in humans than transcriptional. Another control mechanism is the modulation of the noradrenergic stimulation of melatonin secretion by various peptides such as vasoactive intestinal peptide(VIP), neuropeptide Y, pituitary adenylate cyclase-activating peptide (PACAP), and opioides together with GABA, dopamine and glutamate [7].

During the day, noradrenaline released from the postganglionic sympathetic nerve fibres is suppressed because of increased electrical activity in the SCN. In the night, SCN activity is inhibited and the release of noradrenaline is enhanced. Communication between the pineal gland and SCN is bidirectional, the gland communicates with SCN via melatonin. In the absence of light input, the pineal gland rhythms persist but are not entrained to the external light-dark cycle [15].

Drugs As expected, drugs that affect sympathetic activation can alter melatonin secretion. Beta-blocking agents, such as propranolol and atenolol, which interfere with B1-adrenergic stimulation in the pineal gland, cause a reduction of melatonin production. Drugs that stimulate A2-receptors, such as clonidine, will decrease melatonin output, whereas drugs that block these receptors, such as yohimbine, increase its production. Tricyclic antidepressants, which interfere with norepinephrine reuptake, increase the production, too. Many antidepressant treatments stimulate melatonin secretion by acting through increased availability of the precursors tryptophan and serotonin and the major pineal transmitter norepinephrine or by direct action on serotonin and cathecholamine receptors [7].

\section{MELATONIN: IMPLICATIONS IN SLEEP AND AUTISM SPECTRUM DISORDERS}

Melatonin has a major role in diurnal and seasonal rhythms and may regulate circadian gene expression and influence a variety of physiological systems. The most studied role of melatonin is that of phase shifting and resetting circadian rhythms. Most homeostatic activities are also rhythmic, including body temperature, water 
balance, blood volume, sleep and activity. Melatonin via SCN of hypothalamus influences temperature, sleepwake and other rhythmic functions. The temperature nadir correlates closely with the peak of melatonin [15].

In animals melatonin regulates the reproductive axis, including gonadotropic secretion and the timing and onset of puberty, acting in an inhibitory capacity [26]. Melatonin can modulate the ultradian properties of LH and FSH secretion and it acutely increases prolactin rates. The presence of melatonin in ovarian follicular fluid suggests the possibility for a direct effect of the pineal hormone in ovarian function as well.

\section{Melatonin and sleep disorders}

Sleep is controlled by homeostatic and circadian mechanisms. The circadian system controls the timing of sleep onset and offset and the distribution of rapid eye movement (RMN). Sleep and wake performance represent complex behaviours generated by a variety of neuroanatomical structures such as the brainstem, hypothalamus and neocortex. The mechanism by which SCN promotes sleep is still under investigation, however, a number of studies suggest that melatonin is the principal neurochemical agent through which it achieves this. Several lines of evidence have demonstrated the importance of melatonin for the initiation, maintenance and quality of sleep in addition to the sleep- wake rhythm.

The first strong evidence of the sleep-promoting effects of melatonin was provided by Lerner and Case [7]. In an attempt to treat patients with vitiligo, the investigators found that the patients became sleepy after administration. The original study was followed up by studies including polysomnographic (PSG) assessments and a wide range of doses were administered. The investigation used very high doses ranging from 50-1000mg

orally or 200mg intravenously, considered as "pharmacological doses", but also "physiological doses" ranging from 0,1 to $10 \mathrm{mg}$. Administration of 0,1 to $0,3 \mathrm{mg}$ of melatonin, which resulted in circulating melatonin levels less than $200 \mathrm{pg} / \mathrm{ml}$ and close to the maximum levels found at night, promoted sleep in young healthy volunteers. Very high doses did not cause incontrollable sedation or anaesthesia but melatonin decreased wakefulness after sleep onset in some specific studies [7].

The effects of melatonin in sleep initiation normally occur within 30-60 min after administration. The melatonin opens the gate of nocturnal sleepiness by inhibiting the circadian wakefulness-generating mechanism, inhibiting the firing of SCN neurons, effect thought to be mediated by MT1 receptors at the SCN levels and correlated with reduction in brain cAMP levels. Melatonin treatment decreased wakefulness after sleep onset in some specific studies but not in another [33]. 


\section{Melatonin and Autism Spectrum Disorders}

The first biochemical model for autism proposed a hyper secretion of pineal melatonin (5).

In this direction in 1993 the study realised by Ritvo and coll. with adults reported increased daytime urinary melatonin levels and no differences in nocturnal values (38). In 1995 Nir et al. also reported elevated daytime levels of melatonin for young adults with autism spectrum disorders. (30) An inverted melatonin circadian rhythm associated with autistic behaviour was detected in patients with Smith-Magenis syndrome in 1998. (28)

During the last years 6 studies including children found an abnormal decrease of melatonin secretion in subjects with autism but the underlying cause of this deficit and its relationship to susceptibility to ASD were unknown $[21,22,28,29,38,42]$. In 2007 , in a study of a group of 43 subjects with autism, which used a combination of genetic and biochemical approaches suggested that this deficit of melatonin was not a consequence but a primary trait caused by a deficiency in HIOMT (enzyme of the final step of melatonin synthesis) activity. This anomaly observed in some parents indicated that the melatonin deficit by itself could be a risk factor of autism, suggesting a genetic origin in this disorder, even if this anomaly is not sufficient to cause ASD [28].

\section{Melatonin and neuronal plasticity.}

In normal development, synaptic plasticity, the adaptability of neuroanatomic structures and the remodelling of synaptic circuitry diminish substantially during puberty and is attributed to a surge of sex steroids during adolescence. There is also the hypothesis that pineal involution during puberty may contribute to plasticity decay.

In autism, synaptic plasticity, which promotes the acquisition of complex skills such as language, seems to be affected. Autistic children use selective signal processing and exhibit repetitive responses to familiar stimuli but their ability to learn new skills is impaired. The new hypothesis sustains that abnormal physiology and sleep problems in autism, especially the greater fragmentation, may lead to less connectivity, which could furnish a neural substrate for forming a specificity for the processing of information $[6,43]$.

\section{Melatonin and Genetic studies}

Many studies advocated a genetic aetiology of autism and a number of genes regulating the development of the nervous system as the synaptic genes were studied in the last years and were associated with autism. One hypothesis sustains that autism may be due to a problem in the development of a specific pathway controlling the wiring of the neuronal networks. The changes in the number and/or the quality of the synaptic contacts may be subtle, but the consequences at the cognitive level are obvious because patients sometimes present a complete absence of speech. 
Melatonin could modulate neuronal networks by influencing both the strength and the circadian oscillation of neural transmission. Melatonin was shown to modulate the phosphorilation of Krebs considering the key role of Krebs in the memory consolidation and the absence of the melatonin may alter this process. Melatonin inhibits synaptic transmission and long-term potentiation (LTP) in the hippocampus through a mechanism involving MT2 receptors through a modulation of the gaba-ergic system. For T. Bourgeron the emerging role of melatonin in the modulation of the Gaba-ergic system may be the most interesting characteristic, linking melatonin with the susceptibility to autism [4].

\section{MELATONIN SUBSTITUTION IN AUTISTIC SUBJECTS WITH SLEEP DISTURBANCES}

A growing body of evidence shows that childhood sleep disturbances may widely impact children's health, behaviour, attention, cognition and school performance $[6,19]$. Interviews with parents of children with autism revealed than more than $70 \%$ had delayed development of the circadian sleep/wake cycle by at least 5 months. This problem persists through childhood because 50-80\% show increased sleep latency and nocturnal awakenings (bed time resistance, insomnia, parasomnia, sleep disorders breathing, morning rise problems, and day time sleepiness) [28,31,34]. The evidence for abnormal sleep in autism was revealed by questionnaire studies and polysomnographies with abnormalities in REM sleep (including immaturity in the organisation of eye movements into discrete bursts, increased muscle twitches during REM sleep and undifferentiated sleep in which features of non-REM and REM sleep are intermixed [25].

\section{Treatment of sleep disturbances in autism}

Specialists began to use melatonin for children after the first case report in 1991 by Pallm and coll. These authors described the first successful melatonin treatment of a blind, multidisabled child, who had a free-running and markedly fragmented sleep pattern [19].

In 1994, melatonin therapy for children with neurodevelopmental disorders and chronic sleep difficulties was first introduced in the USA where it is considered as a first-line treatment of insomnia. Melatonin is not a licensed drug and it is sold as a nutritional supplement in a variety of preparations but its use grows regularly [39].The pharmacy prepares this medication for children in a capsule form. In France melatonin recently has been licensed for insomnia in adults who are more than 50 years old, but not in children.

A study which measured the attitudes and practices of doctors in the USA show that $25 \%$ of 3100 physicians who participated encouraged the administration of melatonin in children with autism and melatonin is reported to be used by $11 \%$ of children with autism $[1,11]$. 


\section{Studies}

A number of recent studies suggest that melatonin is an effective treatment for circadian rhythm sleep disorders in children. Several investigations of the efficacy and safety of melatonin treatment were conducted particularly for children affected by neurodevelopmental disabilities and ASD, and these studies have produced favourable results [20] (Table 1).

In a recent review of literature, following an evidence-based medicine analysis, efficacy of treatment with melatonin in children with neurodevelopmental disorders is classified as grade B [23]. One year later, another review article identifies melatonin as grade A of recommendation (36). One of the ancient studies published in 1996 by Jan and O'Donnell included the first 100 children treated by melatonin. These children presented with chronic sleep disturbances and various neurodevelopmental and neuropsychiatric disorders, including autism. The ages ranged from 3 months to 21 years. Fast- release synthetic melatonin (FR) was used, taken at bed time, and recommended on an "empty stomach". The dose given was lower for sleep induction and higher for sleep maintenance. The duration of treatment ranged from a few weeks to over 4 years. Complete or partial success from treatment was seen in $82 \%$ cases and approximately $1 / 2$ of sleep patterns improved with the first doses. The more severe the sleep-wake disturbance was, the more beneficial treatment appeared to be. The investigators concluded that melatonin induces and maintains sleep [19].

An investigation by Ishizaki and coll. in 1999 studied the usefulness of melatonin for sleep disorders and emotional/behaviour disturbances in 50 subjects ranging in age from 3 to 28 years and presenting with developmental disorders, including 27 with autism. Behaviours related to excitability were improved, but no changes were observed in stereotyped behaviours and school refusal. The treatment was useful for 34 patients, ameliorating insomnia and circadian rhythm sleep disorders [17].

A small study carried out by Garstang and Wallis in 2006 with a randomized, placebo-controlled, double-blind crossover trial design with melatonin, focused on 11 children with ASD, aged from 4 to 16 years. It provided evidence of the effectiveness of melatonin and mentioned huge difficulties relating to patient recruitment, due to the fact that many local patients were already taking melatonin and so were ineligible for the trial. Several parents commented that their children were easier to manage and less rigid in their behaviour while taking melatonin, and their teachers shared these views [9].

An open clinical trial published in 2006 evaluated long term effectiveness of CR melatonin in 25 children with autism and severe and persistent sleep disorders, ranging in age from 2,6 to 9,6 years. The duration of treatment was 6 months and discontinuation was 1 month later. The dose was $1 \mathrm{mg}$ FR and 2mg CR melatonin. The dose 
was increased to a maximum of $4 \mathrm{mg}$ under 4 years and to a maximum of $6 \mathrm{mg}$ for patients over 6 years of age [10].

During treatment, sleep patterns of all children improved and for some children treatment gains were maintained at 12 and 24-month follow-up, while for others insomnia returned to the pre-treatment score after discontinuation. For these subjects, the reintroduction of melatonin was again effective. The mean onset age of sleep disturbances was 17 months and the mean age of regression was 22 months. The sleep problems started at the same age, suggesting a higher vulnerability during this period of life. Another interesting result regards cosleeping, the practice of parents and children sleeping together in body contact for the whole night, that was reported for $65 \%$ of children with autism as compared to $5 \%$ of controls.

In the same time, the study confirmed the high prevalence of sleep problems in autistic children and highlighted the need for effective intervention, pharmacological and behavioural interventions.

A more recent study carried out in 2008 followed up 47 children with neurodevelopmental disabilities including autistic spectrum disorders, in a randomized placebo-controlled crossover design trial of controlled-release (CR) melatonin. The ages ranged from 2 to 18 years and the dose, 5mg (1mg FR melatonin and 4 mg controlledrelease CR melatonin), was gradually increased for optimal benefits, up to $15 \mathrm{mg}$, followed by 3 months openlabel study. The results show efficacy in delayed sleep phase syndrome and impaired sleep maintenance, with improvement of total sleep and/or onset latency of 30 minutes in all cases. Analysis of patients' variables revealed potential neurological factors underlying melatonin response. The researchers thought that lower doses would have yielded similar results and noted the need for dose studies in the future [39].

A number of parents described an improvement in mood and day time behaviour; the children were less irritable and calmer and in a better mood. Another result was mentioned with a significant improvement of depression, anxiety and withdrawal symptoms during melatonin treatment in children with Asperger Syndrome. No amelioration of scores of Children Autistic Rating Scale (CARS) was observable in this study. In conclusion, the study suggested that CR melatonin in low doses together with behaviour therapy may be useful in children with autism [10].

A large retrospective study realized in the USA in 2008, in a cohort of 107 children, found that melatonin is a safe treatment for both sleep-onset and sleep-maintenance insomnia in children diagnosed with ASD. Coexisting psychiatric diagnoses were reported in $31 \%$ of children, and also concurrent medication. The age of onset of sleep disturbances was $6,7+/-3,8$ years old, the age at which treatment was started was $8+/-3,9$ years and the treatment was followed up 1,8-1,4 years later. Sleep onset insomnia alone was reported for $23 \%$ of subjects, 
sleep maintenance insomnia alone for $8 \%$, the presence of both for $68 \%$ and early awakenings by $1 \%$ of subjects. Children less than 6 years of age started on 0,75 to $1 \mathrm{mg}$ of melatonin. The melatonin was increased by $1 \mathrm{mg}$ every 2 weeks, up to $3 \mathrm{mg}$, if no response was noted at the lower dose. Children older than 6 years of age started with 1,5 mg and if no clinical response was observed 2 weeks later, doses were increased until 3 or $6 \mathrm{mg}$. A beneficial response was noted at melatonin doses of $3 \mathrm{mg}$ or less in many children. The results showed that $60 \%$ of parents reported improved sleep in their child, and $13 \%$ of families continued to report sleep problems as a major concern. In approximately $6 \%$ of cases, despite dose escalation, sleep problems returned after 3-12 months [2].

Among the five randomized, double-blind, placebo-controlled studies, total sleep duration was significantly increased and sleep latency was significantly decreased in children and adolescents with developmental disorders $[9,27,39,40,41]$

\section{Practical guidelines}

The dosage used in clinical studies for children varied from 0,5 to $10 \mathrm{mg}$ taken at the desired bedtime [10], some reports advocating doses of $10 \mathrm{mg}$ or higher [2]. The most common doses employed were 2,5 to $5 \mathrm{mg}$, starting with low doses and increasing gradually. Given its relatively short half-life, melatonin should be given 30 minutes before the desired bedtime. In addition to acting as a hypnotic, it also has a chronobiotic (phase-shift) effect and for individual with delayed sleep phase syndrome it is proposed by researchers, but not all, to be given several hours before bedtime.

Physiological doses $(500 \mu \mathrm{g})$ are effective in causing phase shifts, but doses of 1 to $3 \mathrm{mg}$ are more commonly used because of sedative effects. It is necessary to monitor closely the child for adverse effects because children with autism may be unable to verbally describe side effects. It is important to use the same formulation, as the bioavailability of melatonin may vary widely among manufacturers.

Attempts should be made to discontinue melatonin once a sleep cycle is established for 6 weeks or more, although long-term use appears safe and may be necessary [20].

For the patients in whom the effects of treatment were lost when stopped, readministration was again effective. It could be hypothesized that in these cases melatonin secretion was extremely disturbed.

For other children no relapse was noticed after discontinuation, except slight delay of sleep onset, hypothesizing that circadian control was well reset by melatonin in these cases.

As suggested by Jan and O'Donnell in 1999, some children, whose understanding of the environment is so impaired, periodic melatonin treatment might be necessary throughout their lives [10]. 
The studies show no or minimal side effects and very rare side effects are reported $[2,10,17,20]$.

None of the studies report increases in seizures in autistic children except one in children with profound mental retardation and epilepsy, and another in children with refractory epilepsy.

We notice the hypothesis that the impurities in some melatonin products could generate some adverse effects [10].

The most common adverse events among children receiving CR melatonin were seizures, colds, flu, infection, gastro-intestinal illness and agitation [39]. There is a common concern about long term melatonin treatment in children regarding possible adverse effects on the endocrine system [10]. There are no published reports on this to our knowledge but it is necessary to better understand this problem. It may be wise to periodically withdraw the medication to better evaluate its continuing positive effects and possible adverse effects. Despite these few data, specialized team emphasize the safety of melatonin treatment and its interest for treatment in autism.

\section{Clinical cases}

For the purpose of illustration, we describe with retrospective data, the treatment by melatonin of a small group of autistic children in our department of child and adolescent psychiatry, one of the five departments dedicated to the diagnosis of autistic spectrum disorders in Paris. In 2008, 167 children and adolescents, 2 to 18 years old, were evaluated following an ambulatory procedure but only 6 subjects with autistic spectrum disorder and 1 with Asperger syndrome, in reference to CIM-10 criteria, were treated by melatonin for sleep disorders. They were all males and the mean age at the onset of the melatonin treatment was 7,33 years (3.08-13.16). Parents were interviewed by a child and adolescent psychiatrist, trained in autistic disorders diagnosis. All the subjects of the group had sleep-inducing difficulties and $43 \%$ had nocturnal awakenings. For 5 children melatonin was prescribed as a first intention for sleep disorders. When the treatment was initiated in the department, parents were informed of the benefits and risks of treatment and parental consent was required for initiating therapy. At the onset of the treatment, dosage ranged from $1 \mathrm{mg}$ to $5 \mathrm{mg}$ per day (mean dosage for group was $1,85 \mathrm{mg}$ per day). The effect on sleep-inducing was satisfying in $71 \%$ cases, specifically on the improvement of onset latency and on nocturnal awakenings in $67 \%$ cases. Five children had maintained the melatonin treatment at time of data collection. Melatonin administration was stopped for two of them because of sleep improvement and no relapse was noticed after discontinuation. No side effects were observed for the entire group [3].

\section{DISCUSSION}

Several studies regarding the efficacy and safety of the treatment with melatonin in neurodevelopmental disabilities and autism have been conducted but fewer have focused exclusively on children with autism. 
Few studies, often small case series, examined the effectiveness of therapy using rigorous methodology such as randomization, placebo control and blinded participants and providers.

However the results of those studies were favourable and children with ASD who had co-morbid insomnia were identified as the group with the highest priority for treatment because they have low response rates to other treatments [39].

Results showed that autistic children experience a reduction in sleep latency and improvements in total sleep time and sleep efficiency (time asleep/time in bed).

Although melatonin has not be been rigorously tested for safety, efficacy, or purity of preparation, no serious adverse effects have been seen when using the widely used supplement but investigation of the long term effects of melatonin treatment is necessary [20].

The effects of melatonin were influenced by the type of sleep disturbances, environmental factors, mental conditions and other co-existing treatments.

The fast release synthetic form of melatonin was more effective in improving sleep onset delay and controlledrelease melatonin was more effective with regard to sleep fragmentation, a recent study having shown the effectiveness of the combined form in promoting and maintaining sleep in ASD medication-free children [2]. The more severe the sleep problem, the most beneficial treatment appeared to be [10].

Anxiety was reported to be a problem for all the children with ASD. Amelioration of the disturbed pre-sleep behaviour by treatment may demonstrate the anxiolytic properties of melatonin [39]

The mechanisms by which melatonin promote sleep in people with autism remains unknown. A hypothesis could be that melatonin may act non-specifically as a hypnotic agent to promote sleep. Additionally melatonin may promote sleep by decreasing core body temperature or through anxiolytic mechanisms [20].

The optimal effective melatonin dose is yet unclear and is necessary to carry out dose studies with melatonin level measurement

Blinded placebo control studies are indicated due to other variables (adjustments of doses to clinical response, possible effects of sleep loss for these children, environment, hygiene of sleep, normal fluctuation in autism ) because melatonin may ameliorate the quality of sleep and, indirectly the quality of life of these children and their families $[10,12]$.

\section{CONCLUSION}

Melatonin use for the treatment of sleep disorders in autism seems to be a good alternative to classical treatment with anxiolytics or neuroleptics. It is not considered to be a therapeutic agent but rather a biological complement 
and numerous studies have testified to its efficacy or its inocuity. Further clinical and laboratory research in this field remain necessary with replicated results for inocuity and including more variables as parental quality of life.

Table 1: Results of 17 studies on the effectiveness and side effects of melatonin treatment in autistic subjects

\begin{tabular}{|c|c|c|c|c|c|c|}
\hline STUDY & $\mathrm{N}$ & Age (years) & Dose/Form & $\begin{array}{l}\text { Design of the } \\
\text { study }\end{array}$ & Effectiveness & $\begin{array}{c}\text { Side effects } \\
\% \\
\text { (-) not detailed }\end{array}$ \\
\hline $\begin{array}{l}\text { Jan and coll. } \\
1996\end{array}$ & 100 & $3 m-21$ & $\begin{array}{c}2,5-10 \mathrm{mg} \\
\text { FR }\end{array}$ & Open & + & 0 \\
\hline $\begin{array}{l}\text { Horrigan and } \\
\text { coll., } 1997\end{array}$ & 1 & 17 & $3 \mathrm{mg}$ & Open & + & 0 \\
\hline $\begin{array}{l}\text { McArthur } \\
\text { and coll., } \\
1998\end{array}$ & 9 & $8,5-11,5$ & $2,5-7,5 \mathrm{mg}$ & Randomized & + & 0 \\
\hline $\begin{array}{l}\text { Yamashita } \\
\text { and coll., } \\
1999\end{array}$ & 1 & 10 & $3 \mathrm{mg}$ & Open & + & - \\
\hline $\begin{array}{l}\text { Ishizaki and } \\
\text { coll., } 1999\end{array}$ & 50 & $3-28$ & - & Open & + & 34 \\
\hline $\begin{array}{l}\text { Miyamoto } \\
\text { and coll., } \\
1999 \\
\end{array}$ & 2 & $7-13$ & $3-5 \mathrm{mg}$ & Open & + & 0 \\
\hline $\begin{array}{l}\text { Hayashi and } \\
\text { coll. } 2000\end{array}$ & 1 & 14 & $6 \mathrm{mg}$ & Open & + & - \\
\hline $\begin{array}{l}\text { Paavonen } \\
\text { and coll., } \\
2003\end{array}$ & 15 & $6-17$ & $3 m g$ & Open & + & 27 \\
\hline $\begin{array}{l}\text { Jan and coll., } \\
2004\end{array}$ & 1 & 12 & $5 \mathrm{mg}$ CR & Open & + & - \\
\hline $\begin{array}{l}\text { Gupta and } \\
\text { coll., } 2005\end{array}$ & 9 & $2-11$ & $2,5-5 \mathrm{mg}$ & Open & + & $44-56$ \\
\hline $\begin{array}{l}\text { Garstang and } \\
\text { Wallis, } 2006\end{array}$ & 11 & $4-16$ & $5 \mathrm{mg}$ FR & Randomized & + & - \\
\hline $\begin{array}{l}\text { Giannotti } \\
\text { and coll., } \\
2006\end{array}$ & 25 & $2,5-9,5$ & $\begin{array}{c}3 m g-6 m g \\
C R\end{array}$ & Open & + & 0 \\
\hline $\begin{array}{l}\text { Andersen } \\
\text { and coll., } \\
2008 \\
\end{array}$ & 107 & $2-18$ & $\begin{array}{c}0,75 \mathrm{mg}-6 \mathrm{mg} \\
\text { FR or CR }\end{array}$ & Open & + & 2,7 \\
\hline $\begin{array}{l}\text { Wasdell and } \\
\text { coll., } 2008\end{array}$ & 47 & $2-18$ & $\begin{array}{c}1 \mathrm{mg} \mathrm{FR}+4 \\
\mathrm{mg} \mathrm{CR}\end{array}$ & Randomized & + & 64 \\
\hline $\begin{array}{l}\text { Wirojanan } \\
\text { and coll., } \\
2009\end{array}$ & 12 & $2-15,3$ & $3 \mathrm{mg}$ & Randomized & + & 0 \\
\hline $\begin{array}{l}\text { Beaumanoir } \\
\text { and coll., } \\
2009\end{array}$ & 7 & $3-13$ & $\begin{array}{c}1 \mathrm{mg}-5 \mathrm{mg} \\
\text { FR }\end{array}$ & Open & + & 0 \\
\hline $\begin{array}{l}\text { Wright and } \\
\text { coll., } 2010\end{array}$ & 17 & Mean age 9 & $2-10 \mathrm{mg}$ & Randomized & + & Melatonin=Placebo \\
\hline
\end{tabular}




\section{References}

(1)Aman MG, Lam KS, Collier-Crespin A. Prevalence and patterns of use of psychoactive medicines among individuals with autism in the Autism Society of Ohio. J.Autism Dev. Disord. 2003; 33(5): 527-34.

(2)Andersen IM, Kaczmarska J, McGrew SG, Malow BA. Melatonin for insomnia in children with autism spectrum disorders. J Child Neurol. 2008 May; 23(5): 482-5. Epub 2008 Jan 8.

(3)Beaumanoir C, Mouraeff Y, Doyen C, Colineaux C, Rieu C, Paubel P, Contejean Y, Use of melatonin for the sleep disturbances in children with ASD, Communication accepted for the Brain Congress, Jan 2010.

(4)Bourgeron T. The possible interplay of synaptic and clock genes in autism spectrum disorders. Cold Spring Harb Symp Quant Biol; 2007; 72:645-54.Review

(5)Chamberlain RS, Herman BH. A novel biochemical model linking dysfunction in brain melatonin, proopiomelanocortin peptides, and serotonin in autism. Biol Psychiatry; 1990 Nov 1; 28(9): 773-93. Review

(6)Chen F, Lemonnier E, Lazartigues A, Planche P. Sleep problems and information processing, a “disconnection effect” in autism? Med Hypotheses; 2006; 66(6): 1245-6. Epub 2006 Feb 28

(7)De Groot Jameson, Endocrinology, Edit. Elsevier Saunders, 2006, vol.1, 557-572

(8)Galli-Carminati G, Deriaz N, Bertschy G. Melatonin in treatment of chronic sleep disorders in adults with autism: a retrospective study. Swiiw Med Wkly 2009, 139(19-20): 293-296.

(9)Garstang J, Wallis M. Randomized controlled trial of melatonin for the children with autistic spectrum disorders. Child Care Health Dev. 2006 Sep; 32(5): 585-9

(10)Giannotti F, Cortesi F, Cerquiglini A, Bernabei P. An open-label study of controlled release melatonin in treatment of sleep disorders in children with autism. J Autism Dev Disord; 2006 Aug; 36'6): 741-52.

(11)Golnik AE, Ireland M. Complementary alternative medicine for children with autism: a physician survey. J Autism Dev Disord. 2009 Mar 11

(12) Guénolé F, Baleyte JM. Effectiveness of melatonin for sleep problems in autism spectrum disorders: evidence grows but researches is still needed. J Autism Dev Disord. 2010 Sep;

(13)Gupta R, Hutchins J; Melatonin: un panacea for desperate parents? (Hype or truth) Arc Dis Child. 2005 Sep; 90(9): 986-7.

(14)Hayashi E. Effect of melatonin on sleep-wake rhythm: the sleep diary of an autistic male. Psychiatry Clin Neurosci. 200 Jun; 54(3): 383-4

(15)Henry HL, Norman AW, Encyclopedia of hormones, Academic Press, 2003, vol 2. 631-644.

(16)Horrigan JP, Barnhill LJ.More on melatonin. J Am Acad Child Adolesc Psychiatry 1997 Aug; 36(8): 1014 
(17)Ishizaki A, Sugama M, Takeuchi N. Usefulness of melatonin for developmental sleep and emotional/behaviour disorders-studies of melatonin trial on 50 patients with developmental disorders. No To Hattatsu, 1999 Sep; 31(5): 487-37.

(18 ) Jan JE, Freeman RD, Wasdell MB, Bomben MM. A child with severe night terrors and sleep-walking responds to melatonin therapy. Dev Med Child Neurol 2004, 46(11): 789.

(19)Jan JE, O’Donnell ME. Use of melatonin in the treatment of paediatric sleep disorders. J Pineal Res. 1996 Nov; 21(4): 193-9. Review.

(20)Johnson KP, Malow BA. Assessment and pharmachologic treatment of sleep disturbance in autism. Chil Adolesc Psychiatr Clin N Am 2008 Oct; 17(4): 773-85, Review.

(21)Kulman G, Lissoni P,Rovelli F, Roselli MG, Brivio F, Sequeri P. Evidence of pineal endocrine hypofunction in autistic children. Neuro Endocrinol Lett. 2000; 21(1): 31-34.

(22)Leu RM, Beyderman L, Botzolakis EJ, Surdyka K, Wang L, Malow BA. Relation of melatonin to sleep architecture in children with autism. J Autism Dev Disord, 2010

(23)Levy SE, Hyman SL. Complementary and alternative medicine treatments for children with autism spectrum disorders. Chil Adolesc Psychiatr Clin N Am 2008 Oct; 17(4): 803-20. Review.

(24)Lord C. What is melatonin? It is a useful treatment for sleep problems in autism? J Aut Dev Disord. 1998 Aug; 28(4): 345-6

(25)Malow BA. Sleep disorders, epilepsy and autism. Ment Retard Dev Disabil ResRev. 2004 ; 10(2) : 122-5. Review.

(26)Martini L, Encyclopedia of Endocrine Disease. Elsevier Academic Press. 2003, Vol. 3, 228-237.

(27) McArthur AJ, Budden SS. Sleep dysfunction in Rett syndrome: a trial of exogenous melatonin treatment. Dev Med Child Neurol 1998, 40(3):186-192.

(28)Melke J, Goubran Botros H, Chaste P and coll. Abnormal melatonin synthesis in autism spectrum disorders. Mol Psychiatry, 2008 Jan; 13(1): 90-8.Epub 2007 May.

(29)Miyamoto A, Oki J, Takahashi S, Okuno A. Serum melatonin kinetics and long-term melatonin treatment for sleep disorders in Rett syndrome. Brain Dev 1999, 21(1): 59-62.

(30)Nir I, Meir D, Zilber N, Knobler H, and coll. Brief report: circadian melatonin, thyroid-stimulating hormone, prolactine, and cortisol levels in serum of young adults with autism. J Autism Dev Disord. 1995 Dec; 25(6): 64154.

(31)Owens JA, Rosen CL, Mindell JA. Medication use in the treatment of pediatric insomnia: results of a survey 
of community-based pediatricians. Pediatrics. 2003, May; 111(5Pt 1): e628-35.

(32) Paavonen EJ, Nieminen-von Wendt T, Vanhala R, Aronen ET, von Wendt L. Effectiveness of melatonin in the treatment of sleep disturbances in children with Asperger disorder. J Child Adolesc Psychopharmacol 2003, 13(1):83-95.

(33)Pandi-Perumal SR, Srinivasan V, Spence DW, Cardinali DP. Role of the melatonin system in the control of sleep: therapeutic implications. CNS Drugs. 2007; 21(12):995-1018. Review.

(34)Patzold LM, Richdale AL, Tonge BJ. An investigation into the sleep characteristics of children with autism and Asperger's disorder. J Paediatr Child Health. 1998; Dec. 34(6):528-33.

(35) Reiter RJ, Tan DX, Manchester C, Pilar Terron M, Flores LJ, Koppiespi S. Medical implcations of melatonin receptor-mediated and receptor-independent actions. Adv Med Scien,2007,52:11-28.

(36)Rossignol DA. Novel and emerging treatments for autism spectrum disorders: a systematic review, Ann Clin Psychiatry 2009, 21(4): 213-236.

(37)Rufo-Campos M. Melatonin and epilepsy. Rev Neurol. 2002 Sep; 35 Suppl 1 S51-8. Review.

(38)Tordjman S,Anderson GM, Pichard N, Charbury H, Touitou Y. Nocturnal excretion of 6sulphatoxymelatonin in children and adolescents with autistic disorder. Biol Psychiatry. 2005 Jan 15; 57(2):1348.

(39)Wasdell MB, Jan JE, Bomben MM, Freeman RD, and coll. A randomized, placebo controlled trial of controlled release melatonin treatment of delayed sleep phase and impaired sleep maintenance in children with neurodevelopmental disabilities. J Pineal Res. 2008 Jan; 44(1): 57-64.

(40) Wirojanan J, Jacquemont S, Diaz R, Bacalman S, Anders TF, Hagerman RJ, Goodlin-Jones BI. The efficacy of melatonin for sleep problems in children with autism, fragile $\mathrm{X}$ syndrome, or autism and fragile $\mathrm{X}$ syndrome. J Clin Sleep Med 2009, 5(2): 145-150.

(41) Wright B, Sims D, Smart S, Alwazeer A, Alderson-Day B, Allgar V, Whitton C, Tomlinson H, Bennett S, Jardine $\mathbf{J}$ et all. Melatonin versus placebo in children with autistism spectrum conditions and severe sleep problems not amenable to behaviour management strategies: a randomised controlled crossover trial. J Autism Dev Disord 2010 Juin.

(42)Yamashita Y, Matsuishi T, Murakami Y, Kato H. Sleep disorder in Rett syndrome an melatoni treatment. Brain Dev 1999, 21(8): 570. 
(43)Yun AJ, Bazar KA, Lee PY. Pineal attrition, loss of cognitive plasticity, and onset puberty during the teen years: it is a modern maladaptation exposed by evolutionary displacement? Med Hypotheses. 2004; 63(6): 93950. 